\title{
Childhood Onset Systemic Lupus Erythematosus: How much it is different than in Adults
}

\author{
Ashraf MA Bakr* \\ Mansoura Faculty of Medicine, Chief, Pediatric Nephrology Unit, Mansoura, University Children's Hospital, Mansoura, Egypt
}

\section{Introduction}

Systemic Lupus Erythematosus (SLE) is an autoimmune connective tissue disease with multiple-organ involvement. Although the disease is more common in adults, it is more severe and has a much poorer prognosis in children. SLE begins in childhood or adolescence in approximately $15 \%$ of cases [1]. In young adult women the peak incidence of about 5 in 100000 per year [2,3]. By contrast, in children the overall incidence is about 0.5 in 100000 per year [4,5]. The female/ male ratio increases from 2:1 in prepubertal children to $4.5: 1$ in adolescents and $8: 1$ in adults [6]. In children, most cases of lupus occur after age five, with a peak incidence in late childhood and adolescence [7].

\section{Diagnosis and Classification}

The diagnostic criteria of SLE are the same in both children and adults. Diagnosis of SLE is quite different from its classification. The diagnosis may not fulfill the American College of Rheumatology (ACR) classification criteria which were defined and validated for the purposes of clinical trials and were not specifically developed as diagnostic criteria [8]. This differentiation is highly important to avoid inappropriately delayed treatment waiting for the classification criteria to be fulfilled [9].

Diagnosing SLE in children may be difficult due to multisystem affection and heterogeneity of clinical manifestations. The initial symptoms may be vague and red flags for the pediatrician include an older child or adolescent with any combination of persistent fever, fatigue, anemia, leucopenia, lymphadenopathy, malar or other rash, alopecia, unexplained weight loss, neuropsychiatric symptoms, or unexplained microscopic hematuria or proteinuria [10].

The child patient fulfills classification criteria when presents with four of 11 criteria simultaneously or sequentially as in adults [11]. There have been few large-scale efforts to validate the ACR classification criteria for SLE in the childhood onset population. Ferraz et al. [12] in Brazil examined the sensitivity and specificity of ACR criteria in a group of 103 children with SLE and 101 pediatric patients with other rheumatic diseases. These authors found that the most common criteria were positive ANA, arthritis, immunologic disorder, hematologic disorder, malar rash and photosensitivity. Sensitivity was $96 \%$ and specificity was $100 \%$ in this analysis. These data show that the ACR classification system is accurate when applied to a pediatric population.

\section{Distinctive Clinical Features of Childhood SLE}

One method of measuring disease severity is organ involvement. Compared with adults, children with SLE have more active disease at time of diagnosis and over time. Children have higher rates of organ involvement, develop lupus nephritis at a higher frequency and renal damage more rapid than adults $[13,14]$.

A second method for measuring the disease severity is by categorizing patients according to the amount of corticosteroids used to treat initial disease. Tucker et al. categorized patients who required corticosteroid more than $0.5 \mathrm{mg} / \mathrm{kg} /$ day as high disease severity patients while patients who didn't require corticosteroids were categorized as low disease severity patients. It was found that the higher disease severity category included $77 \%$ of children and only $16 \%$ of adults, while $46 \%$ of adults were categorized as low disease severity and only $13 \%$ of children belonged to this group [15].

A third method for describing disease severity is disease damage. The Rood study used the Systemic Lupus International Collaborating Clinic (SLICC)/ACR damage index to assess damage in a group of children with SLE. The mean index was found to be 2.6 after 4.7 years of follow-up, while an index of 0.75 after 5 years of follow-up was found in adults [16].

Mortality rate is the fourth measure of disease activity. Pediatric deaths mostly occur during the acute phase of the disease, while most adults' deaths are related to disease outcome (organ failure, myocardial infarction) or side effects (infection) [11].

\section{Distinctive Immunologic Features of Childhood SLE}

An increased prevalence of anti-DNA antibodies was reported in the childhood SLE in comparison to the adult SLE (15). In contrast, other studies did not find a significant difference $[13,17]$. These studies found no difference in frequency of presence of ANA and neither of these studies commented on difference in the pattern of ANA (speckled, homogenous, nucleolar or centromere) in the pediatric versus adult population.

Tucker found that anti-Sm antibodies and antibody to the $70 \mathrm{kDa}$ component of RNP are more common in childhood SLE [15]. However, Klein-Gitilman did not confirm this finding [11].

Anticardiolipin frequencies in childhood and adult SLE are similar as reported by most investigators, however, Font et al. [17] described an increased presence of IgG anticardiolipin Ab in childhood SLE. Finally, Tucker study [15] reported an increased frequency of low levels of $\mathrm{C} 3$ at onset compared to adult patients.

\section{Treatment Difficulties in Childhood SLE}

Treatment of childhood onset SLE is a challenge. The therapeutic issues, risks and balances faced by adult patients are much more

*Corresponding author: Ashraf MA Bakr, Mansoura Faculty of Medicine, Chief, Pediatric Nephrology Unit, Mansoura, University Children's Hospital, Mansoura, Egypt, Tel: 0020502230376; E-mail: ashbakr@mans.edu.eg

Received December 09, 2013; Accepted December 10, 2013; Published December 15, 2013

Citation: Bakr AMA (2014) Childhood Onset Systemic Lupus Erythematosus: How much it is different than in Adults. Clinics Mother Child Health 11: e103. doi: 10.4172/2090-7214.1000e103

Copyright: (c) 2014 Bakr AMA. This is an open-access article distributed under the terms of the Creative Commons Attribution License, which permits unrestricted use, distribution, and reproduction in any medium, provided the original author and source are credited. 
Citation: Bakr AMA (2014) Childhood Onset Systemic Lupus Erythematosus: How much it is different than in Adults. Clinics Mother Child Health 11: e103. doi: 10.4172/2090-7214.1000e103

complicated in children with SLE by an unpredictable disease course and long requirement for therapy. Non-compliance is a major obstacle to satisfactory outcome which must be recognized and dealt with in every patient to attain optimal outcome [18]. Unfortunately, there have been no randomized controlled trials in children to assess the drugs currently used in the treatment of pediatric SLE. Data therefore, come from uncontrolled studies, case reports, and extrapolation from the experience with adults with SLE.

In conclusion, the presentation, clinical symptoms and immunological findings of childhood SLE are similar to those of adult SLE patients; however children usually have a more severe disease at onset. They also have higher rates of organ involvement, and a more aggressive clinical course than adults.

\section{References}

1. Tucker LB (2002) Controversies and advances in the management of systemic lupus erythematosus in children and adolescents. Best Pract Res Clin Rheumatol 16: 471-480.

2. Hochberg MC (1985) The incidence of systemic lupus erythematosus in Baltimore, Maryland, 1970-1977. Arthritis Rheum 28: 80-86.

3. Fessel WJ (1988) Epidemiology of systemic lupus erythematosus. Rheum Dis Clin North Am 14: 15-23.

4. Pelkonen PM, Jalanko HJ, Lantto RK, Mäkelä AL, Pietikäinen MA, et al. (1994) Incidence of systemic connective tissue diseases in children: a nationwide prospective study in Finland. J Rheumatol 21: 2143-2146.

5. Malleson PN, Fung MY, Rosenberg AM (1996) The incidence of pediatric rheumatic diseases: results from the Canadian Pediatric Rheumatology Association Disease Registry. J Rheumatol 23: 1981-1987.

6. Cameron JS (1999) Lupus nephritis. J Am Soc Nephrol 10: 413-424.
7. Platt JL, Burke BA, Fish AJ, Kim Y, Michael AF (1982) Systemic lupus erythematosus in the first two decades of life. Am J Kidney Dis 2: 212-222.

8. Malleson PN and Tekano J (2007) Diagnosis and management of systemic lupus erythematosus in children. Paediatrics and Child Health 18: 2.

9. Hochberg MC (1997) Updating the American College of Rheumatology revised criteria for the classification of systemic lupus erythematosus. Arthritis Rheum 40: 1725.

10. Levy DM and Kamphuis S (2012) Systemic lupus erythematosus in children and adolescents. Pediatr Clin North Am 59: 345-364.

11. Klein-Gitelman M (2004) Pediatric lupus versus adult lupus role of the laboratory. Clin Rev Allergy Immunol 4: 333-350.

12. Ferraz MB, Goldenberg J, Hilario MO, Bastols WA, Oliveira SK, et al. (1994) Evaluation of the 1982 ARA lupus criteria data set in pediatric patients. Clin Exp Rheumatol 12: 83-87.

13. Brunner HI, Gladman DD, Ibañez D, Urowitz MD, Silverman ED (2008) Difference in Disease Features Between Childhood-Onset and Adult-Onse Systemic Lupus Erythematosus. Arthritis Rheum 85: 556-562.

14. Bakr A (2005) Epidemiology treatment and outcome of children systemic lupus erythematosus in Egypt. Pediatr Nephrol 20: 1081-1086.

15. Tucker LB, Menon S, Schaller JG, Isenberg DA (1995) Adult and childhood onset systemic lupus erythematosus: a comparison of onset, clinical features, serology and outcome. Br J Rheumatol 34: 866-872.

16. Rood MJ, ten Cate R, van Suijlekom-Smit LW, den Ouden EJ, Ouwerkerk FE, et al. (1999) Childhood-onset systemic lupus erythematosus: clinical presentation and prognosis in 31 patients. Scand J Rheumatol 28: 222-226.

17. Font J, Cervera R, Espinosa G, Pallarés L, Ramos-Casals M, et al. (1998) Systemic lupus erythematosus (SLE) in childhood: analysis of clinical and immunological findings in 34 patients and comparison with SLE characteristics in adults. Ann Rheum Dis 57: 456-459.

18. Macdermott EJ, Adams A, Lehman TJA (2007) Systemic lupus erythematosus in children: current and emerging therapies. Lupus 16: 677-683. 